\title{
Diagnostic dilemma; report of a bizarre case of advanced scalp and face angiosarcoma and literature review
}

This article was published in the following Dove Press journal:

International Medical Case Reports Journal

4 November 2011

Number of times this article has been viewed

\author{
Jude-Kennedy C Emejulu' \\ Igwebuike V Onyiaorah ${ }^{2}$ \\ Cornelius O Ukah ${ }^{2}$ \\ Titus OG Chukwuanukwu ${ }^{3}$ \\ Nneka JF Osuigwe' \\ Effiong E Akang ${ }^{4}$ \\ Adefolarin $O$ Malomo $^{5}$
}

'Neurosurgery Unit, Department of Surgery, Nnamdi Azikiwe University Teaching Hospital, PMB 5025 Nnewi, Anambra State, Nigeria; ${ }^{2}$ Department of Pathology, Nnamdi Azikiwe University Teaching Hospital, PMB 5025 Nnewi, Anambra State, Nigeria; ${ }^{3}$ Plastic Surgery Unit, Department of Surgery, Nnamdi Azikiwe University Teaching Hospital, PMB 5025 Nnewi, Anambra State, Nigeria; ${ }^{4}$ Department of Pathology, University College Hospital, Ibadan, Oyo State, Nigeria; ${ }^{5}$ Department of Neurological Surgery, Institute of Neurological Sciences, University College Hospital, Ibadan, Oyo State, Nigeria
Correspondence: Jude-Kennedy C Emejulu Neurosurgery Unit, Department of Surgery, Nnamdi Azikiwe University Teaching Hospital, PMB 5025 Nnewi, Anambra State, Nigeria Tel +2348033283976

Email judekenny2003@yahoo.com

\begin{abstract}
A 36-year-old male painter presented to our service in 2007 with an ulcerated solitary scalp swelling of 8 months' duration. The mass was a dormant, painless, pea-sized growth, which he had had since childhood and which he bruised in a passenger motorcycle road traffic accident 8 months prior to presentation. The accident caused it to flare up and progressively increase in size, with associated pain, contact bleeding, and ulceration. A work-up for excision biopsy was proposed, but the patient defaulted and presented 2 years later with an increased number of lesions all around the scalp and face and in an obviously deteriorating clinical status with regional lymph node involvement at this stage. An incisional biopsy was then carried out and the histological reports came out with three different diagnoses of glioblastoma multiforme, poorly differentiated angiosarcoma, and squamous cell carcinoma, constituting a major diagnostic dilemma for our service.
\end{abstract}

Keywords: angiosarcoma, glioblastoma multiforme, head, neck, squamous cell carcinoma

\section{Introduction}

Angiosarcomas of the face and scalp are very rare, insidious in onset, and primarily affect older persons. Their clinical manifestations vary widely and in early stages they frequently appear to be clinically innocent. ${ }^{1}$ The lesions may be single or multifocal; bluish or violaceous; nodules, plaques, or flat infiltrating areas; and occasionally bleed or ulcerate. Most early lesions begin as ill-defined bruise-like areas with an indurated border, but more advanced lesions can be elevated, nodular, or occasionally ulcerated. ${ }^{1}$ Histological diagnosis may be confusing, as they may resemble melanomas or carcinomas.

We present a case of advanced angiosarcoma of the face and scalp in a relatively young man, the first and only such case in our 6-year-old Neurosurgery Unit. The lesion presented initially as a discrete, benign-looking nodule that was neglected for 2 years until it spread widely, resulting in multiple scalp and facial lesions and posing a major histological diagnostic dilemma in our hospital. There is no publication that we could find on this rare lesion in Nigeria, so we report probably the first case of advanced angiosarcoma of the scalp and face.

\section{Case report}

A 36-year-old male painter presented to our service in 2007 with an ulcerated solitary scalp swelling of 8 months' duration. The mass was a dormant, painless, pea-sized growth, which he had had since childhood but which he bruised in a passenger 
motorcycle road traffic accident 8 months prior to presentation. The accident caused it to flare up and progressively increase in size, with associated pain, contact bleeding, and ulceration. There were no neurological symptoms, previous surgeries, blood transfusion, or positive family history of a similar lesion.

On clinical examination, the patient was otherwise healthy looking, fully conscious, and alert, with no neurological deficits or regional lymph node enlargement. There was a discrete, firm right frontal scalp mass, which was slightly pulsatile and moderately tender, with purulent discharge and heaped up edges but not attached to underlying bone. Other systems were clinically normal. The clinical diagnosis we made was that of a possible soft-tissue sarcoma or hamartoma.

We proposed a work-up for excision biopsy, but the patient defaulted on follow-up and the biopsy was not carried out. He presented 2 years later with an increased number of lesions all around the scalp and face and in an obviously deteriorating clinical status marked by pallor; significant weight loss; and foul-smelling, purulent, and slough-filled lesions with tender indurated bases. The regional lymph nodes had become infiltrated by this time, and a clinical diagnosis of advanced soft-tissue sarcoma was made at this stage. The lesions followed a longitudinal, vascular, or neural disposition round the face, appearing to encircle it (see Figure 1).

Hematological profile, electrolytes/urea/creatinine, and plasma glucose were normal, HIV screening was nonreactive, and enhanced cranial computed tomography showed isodense extracranial soft-tissue masses with homogenous contrast enhancement but no intracranial lesion or bony involvement. An incisional biopsy was then done at this time, harvesting four wedge specimens from representative parts of the lesions, including the edges of the ulcers and nearby normal-looking skin. The masses were briskly and intensely hemorrhagic on incision.

The first histology report diagnosed glioblastoma multiforme (GBM), but we had our doubts and needed a reconfirmation. The second report diagnosed poorly differentiated angiosarcoma. In seeking to resolve the dilemma, we sent a third specimen to another facility with a neuropathologist. The last report stated the tumour consisted of polygonal cells with abundant eosinophilic cytoplasm, focal dyskeratosis, acantholysis, and surface keratinization. Cells were positive for epithelial markers (AE1/AE3) and negative for vascular markers (CD31 and CD34). Morphologically, the tumor was not a glioblastoma and the report diagnosed squamous cell carcinoma (see Figure 2).

While awaiting the neuropathologist's report, the patient was serially transfused with blood due to persistent anemia. However, he progressively deteriorated and finally died in April 2010, about 3 years after his first presentation to our service.

\section{Discussion}

After several brainstorming sessions and a clinical conference, we finally agreed that the overwhelming evidence in this very confusing case weighed in favor of angiosarcoma and not GBM or squamous cell carcinoma.

Angiosarcomas are rare vascular tumors, but in the few cases where they present, the majority are in the skin and especially in the head and neck, a region where sarcomas constitute barely $1 \%$ of malignancies. ${ }^{2}$ The cells manifest many of the morphologic and functional properties of normal epithelium and vary from highly differentiated tumors to those with significant anaplasia, often making these tumors difficult to differentiate from melanomas or carcinomas. $^{3}$
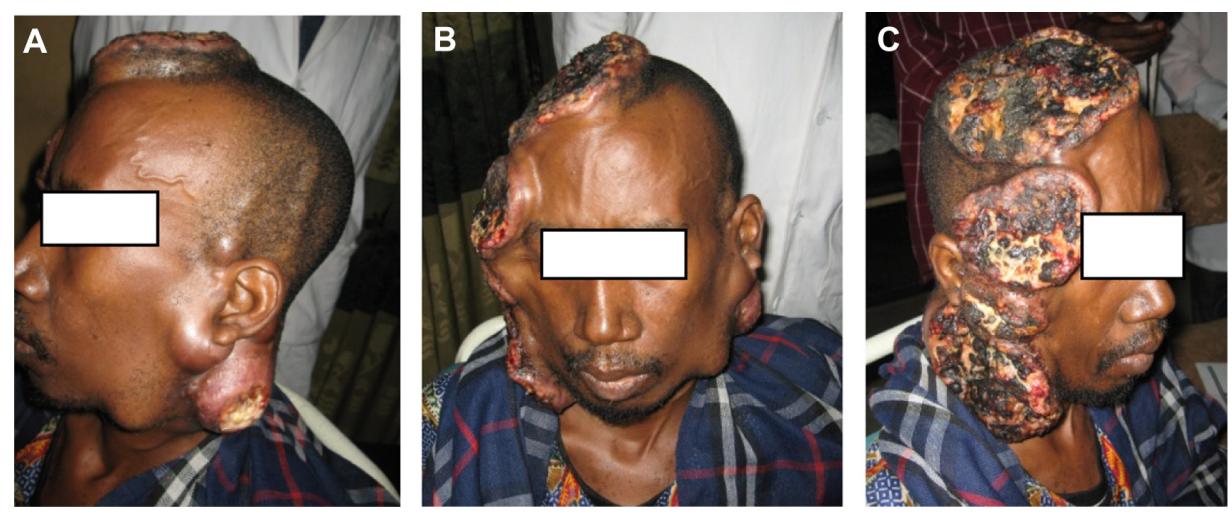

Figure I Views of the lesion: left, front, and right sides. 

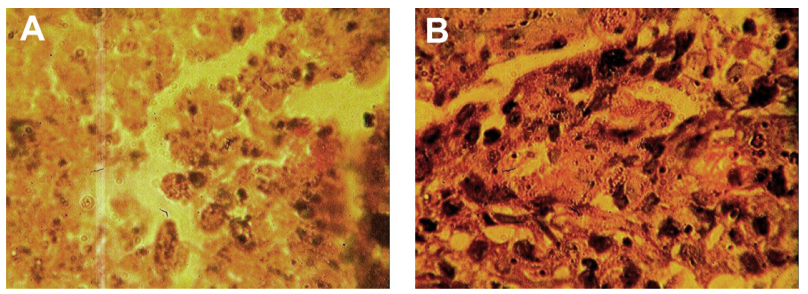

Figure 2 Histology photomicrographs of the patient, showing abundant eosinophilic cytoplasm and some poorly differentiated vascular channels lined by a few endothelial cells.

Aust et $\mathrm{al}^{3}$ reported less than $5 \%$ of soft tumor sarcomas occurring in the head and neck, with only approximately $10 \%$ being angiosarcomas. Being the only such case in our service in a period of 6 years, our experience appears to support the rarity of this malignancy. By contrast, squamous cell carcinomas are the second most common carcinoma of the skin, after basal cell carcinoma, constituting about $90 \%$ of all head and neck malignancies. ${ }^{4}$

Even though GBM is the most frequent primary brain tumor, accounting for approximately $12 \%-15 \%$ of all intracranial neoplasms and $50 \%-60 \%$ of all astrocytic tumors, the extracranial metastasis of GBM is rare and is usually observed after the tumor has infiltrated the dural veins, the cranium, or the extracranial soft tissue or, more frequently, after tumor debulking surgery for a recurrent tumor. ${ }^{5}$

There are only a few case reports of extracranial metastasis of primary GBM to various organs such as the spleen, skin, heart, bone, cervical lymph nodes, and lung. ${ }^{6-14}$ In all these cases the metastases occurred after resection of the primary intracranial tumor with an average time interval of 10 months. Only one case of a spontaneous metastasis of primary GBM to lungs is reported. ${ }^{13}$

The diagnosis in most of these cases was based on biopsy and immunophenotyping with glial fibrillary acidic protein (GFAP). This is suggestive of the fact that most, if not all, cases of extracranial glioblastoma are sequel to an intracranial type. Our patient had no intracranial tumor. His lesion might be least likely to have an extracranial GBM.

Unlike most soft-tissue sarcomas that are located deeply, angiosarcomas have a predilection for skin and superficial soft tissue, just like squamous cell carcinoma. Even though they are usually found on the scalps of elderly people, Aust et $\mathrm{al}^{3}$ reported an age range of 18-91 years in a series of 24 patients treated in the Mayo Clinic, Rochester, MN over an 18-year period, 1974-1992.

On the other hand, the incidence of squamous cell carcinoma varies with age, gender, race, geography, and genetics, unlike the case with an angiosarcoma, though it is thought to definitely rise with age, and the peak incidence is usually around 66 years of age. ${ }^{15,16}$

Etiologically, chronic lymphedema is the most widely recognized predisposing factor for angiosarcomas of the skin and soft tissue, but, according to Weiss and Goldblum, ${ }^{17}$ only approximately $10 \%$ of tumors are associated with lymphedema. Also, Sondak et $\mathrm{al}^{1}$ contend that lymph stasis is probably not involved significantly in angiosarcoma of the scalp.

Several associations have been reported for scalp angiosarcoma, the most frequent being prior radiation for either a malignant or benign condition, whereas others include trauma and ultraviolet light exposure to the hairless parts of the head and neck. ${ }^{18}$ Holden et $\mathrm{al}{ }^{19}$ have, however, questioned the assertion of sun exposure as a tumorigenic agent, because many patients who develop angiosarcomas are women with a full head of hair.

In our case, the absence of lymphedema correlated with the observations of Weiss and Goldblum and others, and, interestingly, trauma seemed be the reason the lesion became noticed by our patient and probably played a definite role. The pea-size nodule had been dormant for nearly 25 years until the motorcycle accident bruised the nodule. Could it be possible that trauma caused the rapid progression of a malignant disease or that it induced the malignant transformation of a benign lesion?

With squamous cell carcinoma, chronic sun exposure is known to be the strongest environmental risk factor, though lesions of the head and neck are most commonly associated with the use of alcohol and tobacco, as well. ${ }^{20}$ The results of one study actually confirmed that tobacco and alcohol use are the main risk factors for the development of head and neck squamous cell carcinoma and affect overall patient survival. ${ }^{21}$ None of these is strongly implicated in angiosarcoma.

Correlating strongly with our case, angiosarcoma of the face and scalp is insidious in onset and in the early stages appears to be clinically innocent. It may be single or multifocal; be bluish or violaceous; have nodules, plaques, or flat infiltrating areas; and occasionally may bleed or ulcerate, according to Sondak et al. ${ }^{1}$ Most early lesions begin as ill-defined bruise-like areas with an indurated border, but the more advanced lesions can be elevated, nodular, or occasionally ulcerated with ill-defined hemorrhagic areas. This morphologic evolution was classic in our case.

In squamous cell carcinoma, the clinical appearance is highly variable. Usually, the tumor presents as an ulcerated lesion with hard, raised edges, and it may be in the form of 
a hard plaque or a papule, often with an opalescent quality, with tiny blood vessels. The tumor could lie below the level of the surrounding skin and eventually ulcerate and invade the underlying tissue. ${ }^{20}$

Microscopically, angiosarcomas often show extensive involvement of the dermis, with poorly differentiated tumors also invading deep structures such as fascia and subcutis. Their histopathologic features are diverse, with three histologic patterns viz. vascular channels, sheets of cells, and cells of undifferentiated morphologic features, although in some lesions more than one pattern may be present. ${ }^{1}$

It should be noted, nonetheless, that low-grade tumors are well-differentiated lesions that retain some of the functional and morphologic properties of normal vascular endothelium, but the poorly differentiated (high-grade) tumors show sheets of pleomorphic cells that may resemble a carcinoma. In other words, the absence of normal vascular epithelium does not exclude the possibility of angiosarcoma, especially in poorly differentiated cases. This may have explained the deft exclusion of angiosarcoma by the third pathology report in our case, while opting instead for squamous cell carcinoma. ${ }^{1}$ However, it was very likely that what we had was more in keeping with the second histologic diagnosis of a poorly differentiated angiosarcoma.

Cytologically, the smears of GBM show large, spindle to oval, hyperchromatic and pleomorphic nuclei. A fibrillary or necrotic background is also noticed in some of these tumor cells of GBM and may be recognizable as astrocytic. ${ }^{22}$ But due to the marked pleomorphism of cohesive groups of tumor cells with frequent mitoses, the recognition of GBM from other poorly differentiated tumors may be quite challenging, supporting the first pathological diagnosis in our case.

The tumor cells of GBM are immunoreactive for GFAP and vimentin. ${ }^{23}$ Vimentin immunoreactivity is nondiagnostic due to the significant overlap with other lesions in the differential diagnosis of poorly differentiated tumors.

Gliosarcoma is another rare subtype of GBM and shows a characteristic biphasic appearance, consisting of a GBM component admixed with sarcomatous elements. This probably did not complicate this case under discussion. ${ }^{24,25}$

In summary, therefore, our case presented initially as a clinically benign lesion that exacerbated after trauma and rapidly extended locally over the face and scalp, showing largely undifferentiated histologic features, before ultimately leading to death within 3 years of onset.

\section{Conclusion}

With the correlations in the evolution of the lesion, its macroscopic and microscopic characteristics, progression, and outcome, we concluded that ours was a case of advanced poorly differentiated angiosarcoma of the scalp that extended to the face, which was supported by the second histology report. It was less likely to be a GBM or squamous cell carcinoma because, to a great extent, the features of the lesion did not correlate with these two.

The disease followed the natural history of angiosarcoma, so we are reporting this case in order to add this confusing experience to the body of knowledge that is already available on this rare disease of poor prognosis, especially with the bizarre images it presented. Ours is possibly the first such case to be reported from Nigeria.

\section{Disclosure}

The authors have no conflict of interests in this publication.

\section{References}

1. Sondak VK, Pawlik TM, Rees SR, et al. Skin: angiosarcoma of the scalp. eMedicine. 2008. Available at: http://emedicine.medscape.com/ article/1296442-overview. Accessed September 21, 2011.

2. Medscape's Skin Cancer Resource Center. http://www.medscape.com/ resource/skincancer.

3. Aust MR, Olsen KD, Lewis JE, et al. Angiosarcomas of the head and neck: clinical and pathologic characteristics. Ann Otol Rhinol Laryngol. 1997;106:943-951.

4. http://www.macmillan.org.uk/Cancerinformation/Cancertypes/ Headneck/Aboutheadneckcancers/Typesofheadneckcancer.aspx.

5. Tamiya YT, Meguro T, Ichikawa T, et al. Glioblastoma with metastasis to spleen: case report. Neurologica Medico-Chirurgica. 2003;43: 452-456.

6. Hata N, Katsuta T, Inoue T, et al. Extra-cranial metastasis of glioblastoma to lung and heart with a histological resemblence to small cell carcinoma of the lung: an autopsy case. No Shinkei Geka. 2001;29: 438-448.

7. Figuera $P$, Lupton JR, Remington T, et al. Cutaneous metastasis from an intracranial glioblastoma multiforme. J Am Acad Dermatol. 2002;46: 297-300.

8. Campora RG, Salverri CO, Ramirez FV, et al. Metastatic glioblastoma multiforme in cervical lymph nodes. Report of a case with diagnosis by fine needle aspiration. Acta Cytological. 1993;7:938-942.

9. Granjon O, Lange F, Aurtheir FJ, Lebragy F. Pulmonary metastases of glioblastoma. Rev Mal Respir. 1995;12:489-491.

10. Al-Rikabi AC, Al-Sohaibani MO, Jamjoom A, Al-rayess MM. Metastatic deposits of a high-grade malignant glioma in cervical lymphnode diagnosed by fine-needle aspiration cytology-case report and literature review. Cytopathology. 1997;8:421-427.

11. Laraqui L, Amarti A, Zouaidia F, et al. Pulmonary metastasis from a glioblastoma: a case report. Rev Pneumol Clin. 2001:225-228. French

12. Chung YH, Wong SL, Huang HY. Endobronchial metastasis of glioblastoma multiforme diagnosed by fiber-optic bronchoscopic biopsy. J Formos Med Assoc. 1999;98:133-135.

13. Greif J, Horovitz M, Marmor S. Pleuropulmonary metastasis from an intracranial glioblastoma. Lung Cancer. 1998;20:135-137.

14. Vural G, Hagmar B, Walaas L. Extra-cranial metastasis of glioblastoma multiforme diagnosed by fine-needle aspiration: a report of 2 cases and a review of literature. Diag Cytopathol. 1996;15:60-65. 
15. Leiter U, Garbe C. Epidemiology of melanoma and nonmelanoma skin cancer: the role of sunlight. Adv Exp Med Biol. 2008;624:89-103.

16. Masini C, Fuchs PG, Gabrielli F, et al. Evidence for the association of human papillomavirus infection and cutaneous squamous cell carcinoma in immunocompetent individuals. Arch Dermatol. 2003;139: 890-894.

17. Weiss SW, Goldblum JR. Malignant vascular tumors. In: Enzinger and Weiss's Soft Tissue Tumors. 4th ed. St. Louis, MO: Mosby; 2001: 917-932.

18. Lydiatt WM, Shaha AR, Shah JP. Angiosarcoma of the head and neck. Am J Surg. 1994;168:451-454.

19. Holden CA, Spittle MF, Jones EW. Angiosarcoma of the face and scalp, prognosis and treatment. Cancer. 1987;59:1046-1057.

20. Cutaneous squamous cell carcinoma. http://www.aad.org/public/ publications/pamphlets/sun_squamous.html.
21. Farshadpour F, Kranenborg H, Calkoen EV, et al. Survival analysis of head and neck squamous cell carcinoma: Influence of smoking and drinking. Head Neck. 2011;33:817-823.

22. Burger P, Scheithauer B. Tumors of the central nervous system: atlas of tumor pathology, Series 3, Fascicle 10. Washington, DC: AFIP; 2007.

23. Atkinson B. Atlas of diagnostic cytopathology. Philadelphia, PA: Saunders; 1991.

24. Yokoyama H, Ono H, Mori K, et al. Extracranial metastasis of glioblastoma with sarcomatous component. Surg Neurol. 1985;24: 641-645.

25. Liwnicz B, Henderson K, Masukawa T, Smith R. Needle aspiration cytology of intracranial lesions. Acta Cytologica. 1982;26:779-786.

\section{Publish your work in this journal}

The International Medical Case Reports Journal is an international, peer-reviewed open-access journal publishing original case reports from all medical specialties. Previously unpublished medical posters are also accepted relating to any area of clinical or preclinical science. Submissions should not normally exceed 2,000 words or
4 published pages including figures, diagrams and references. The manuscript management system is completely online and includes a very quick and fair peer-review system, which is all easy to use. Visit http://www.dovepress.com/testimonials.php to read real quotes from published authors.

Submit your manuscript here: http://www.dovepress.com/international-medical-case-reports-journal-journal 